considerably as the temperature falls further. We estimate its value at $T_{g}$ as greater than $16 \mathrm{kcal} . / \mathrm{gm}$. mol. (a minimum figure obtained by a linear extrapolation between $0^{\circ} \mathrm{C}$. and $T_{g}$ ); it will be noted that this is considerably greater than the latent heat of evaporation $\left(9.7 \mathrm{kcal} . / \mathrm{gm}\right.$. mol. at $100^{\circ} \mathrm{C}$.).

It is well known ${ }^{20-22}$ (see also table) that the activation energy for viscous flow, $E_{\text {visc., }}$ is large and increases continuously with falling temperature for liquids which are able to form glasses. These liquids are characterized by low co-ordination and markedly 'structural' nature and owe their coherence to strongly directed bonds such as the 'hydrogen bond' (in water, alcohols, etc.) or the ionic-homopolar Si-O bond (in silica). As shown by A. G. Ward ${ }^{20}$, the increase of $E_{\text {visc. with falling temperature }}$ implies an increase in structural character-a change actually observed by Bernal and Fowler ${ }^{23}$ in X-ray studies on water.

Values of $E_{\text {visc. }}$ greater than the latent heat of evaporation $\left(L_{\text {vap. }}\right)$ do not appear to have been reported previously, on account of the difficulty of measuring $E_{\text {visc. }}$ for low-temperature glasses and

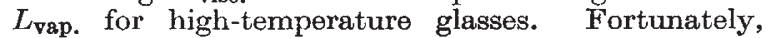
however, the viscosities of three alcohols have been measured nearly to $T_{g}{ }^{24}$, and in the accompanying table we list our own estimate, made from the published graphs, for $E_{\text {visc. at }} T_{g}$ for these liquids, together with values of $L_{\text {vap. }}$ and some other data of interest.

It will be seen that in $n$-propyl alcohol, iso-butyl alcohol and glycerol, as in water, $E_{\text {visc. can greatly }}$ exceed $L_{\text {vap at low temperatures (the variation in }}$ $L_{\text {vap. }}$ with temperature is relatively small and does not affect the argument). This supports the suggestion of various authors $20,21,27,28$ that the flow process in these liquids involves the breaking of strongly directed bonds rather than the movement of molecules. (In 'normal' liquids such as the metals, 'rare gases', non-polar organic substances and ionic salts,

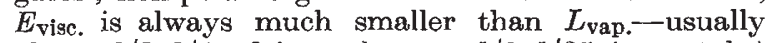
about $1 / 3-1 / 4$ of its value, or $1 / 8-1 / 25$ in metals.) In the case of silica, $E_{\text {visc. at }} T_{g}$ is about twice the energy of the only type of bond present, the Si-O bond ( $\sim 90 \mathrm{kcal} . / \mathrm{gm}$. mol.), and for water and these alcohols it is 3-4 times greater than the strength of the hydrogen bond from hydroxyl groups $(6-8 \mathrm{kcal}$.) gm. mol.) which is assumed to be responsible for their cohesion $^{29-31}$. In glucose, which has a complicated molecule containing five hydroxyl groups, the value of $E_{\text {visc. }}$ is remarkably high.

\section{Conclusion and Summary}

In spite of the great difficulty of producing completely vitreous pure water, there is evidence that under favourable conditions water forms a glass, with the transformation temperature $T_{g}$ lying between $-150^{\circ}$ and $-125^{\circ} \mathrm{C}$. The main implication of this conclusion is that the increase in structural character of water with falling temperature, already detectable above $0^{\circ} \mathrm{C}$., must continue to a very marked extent as the temperature is lowered still further. As in other liquids containing directed bonds, the value of activation energy for viscous flow can exceed the heat of evaporation and the strength of a single bond by a large factor.

An unexpected result is that specimens of glassy water containing varying proportions of crystalline ice complete their crystallization (apparently into ice I) precipitately when the temperature is raised to $-129^{\circ} \mathrm{C}$.
We acknowledge the interest and collaboration of Prof. F. E. Simon, of the Clarendon Laboratory, Oxford, in the early stages of this work, and later the help and facilities given us by Prof. H. R. Robinson, at Queen Mary College, London, and the careful work of Mr. W. A. G. Baldock in making the calorimeters used in the experiments. We are indebted to the Central Research Fund of the University of London for the loan of apparatus, and to Imperial Chemical Industries, Ltd., for a grant-in-aid.

1 Douglas, R. W., and Izard, J. O., J. Soc. Glas8 Tech., 85, 206 (1951). ${ }^{2}$ Luyet, B. J., Phys. Rev., 56, 1244 (1939).

s Luyet, B. J." "Temperature ; its Measurement and Control" (Reinhold, 1947).

4 Burton, E. F., and Oliver, W. F., Proc. Roy. Soc., A, 153, 166 (1935).

'Dobson, G. M. B., Brewer, A. W., and Cwilong, B. M., Proc. Roy. Soc., A, 185, 144 (1946).

- Brewer, A. W., Cwilong, B. M., and Dobson, G. M. B., Proc. Phys. Soc., 60, 52 (1948).

7 Jones, G. O., “Rep. Phys. Soc. Proz. Phys.", 12, 133 (1948-49).

B Jones, G. O., and Simon, F. E., Endeavour, 8, 175 (1949).

- Simon, F. E., Z. Anorg. Allgem. Chem., 208, 219 (1931).

${ }^{10}$ Dorsey, N. E., Trans. Amer. Phil. Soc., 38, 247 (1948).

${ }^{11}$ Cwilong, B. M., Proc. Roy. Soc., A, 190, 137 (1947).

${ }^{12}$ Rau, W., Schrift. Deut. Akad. Luft., 8, 65 (1944).

is König, Н., Z. Rrist., 105, 279 (1944).

${ }^{14}$ Parks, G. S., and Huffman, H. M., J. Phys. Chem., 31, 1842 (1927).

${ }^{15}$ Turnbull, D., J. App. Phys., 21, 1022 (1950).

${ }^{16}$ Kobeko, E.. Kuwshinsky, E., and Shishkin, S., Acta Physicochim. U.R.S.S.. 6, 255 (1937).

${ }^{17}$ Kobeko, E., Phys. Z. der Sowjetunion. 4, 83 (1933).

${ }^{18}$ Tammann, G., "Der Glaszustand" (Leipzig, 1933).

1 Dorsey, N. E., "Properties of Ordinary Water-substance" (Reinhold, 1940).

${ }^{20}$ Ward, A. G., Trans. Farad. Soc., 33, 88 (1937).

${ }^{21}$ Ewell, R. H., and Eyring, H., $J$. Chem. Phys., 5, 726 (1937).

22 Barrer, R. M., Trans. Farad. Soc., 39, 48 (1943).

${ }^{23}$ Bernal, J. D., and Fowler, R. H., J. Chem. Phys., 1, 515 (1933).

${ }^{24}$ Kobeko, E., Kuwshinsky, E., and Shishkin, S., Tech. Phys. U.S.S.R., 5,413 (1938).

${ }^{25}$ Davies, R. O., and Jones, G. O., "The Irreversible Transformation in Glasses" "(to be published).

${ }^{26}$ Parks, G. S., Barton, I. E., Spaght, M. E., and Richardson, J. W., Physics, 5, 193 (1934).

${ }^{27}$ Kinkaid, J. F., Eyring, H., and Stern, E. A., Chem. Rev., 28, 301 (1941).

${ }^{28}$ Harrap, B. S., and Heymann, E., Chem. Rev., 48, 45 (1951).

${ }^{29}$ Owston, P. G., Quart. Rev. Chem. Soc., 5, 344 (1951).

${ }^{30}$ Kellner, L., "Rep. Phys. Soc. Prog. Phys.", 15, 1 (1952).

${ }^{31}$ Pople, J. A., Proc. Roy. Soc., A, 205, 163 (1951).

\section{FACTORS INFLUENCING CHANGE IN HUMAN BEHAVIOUR}

A FULL morning's session at the recent Belfast meeting of the British Association was devoted to the problems of "Resistance to Change", more especially resistance to the application of well-founded scientific knowledge in industry and agriculture. In the first half of the morning some of the more general questions were discussed by Section $J$ (Psychology) ; in the second part of the proceedings, this Section joined with Section M (Agriculture) in a symposium on resistance to change in farming. Most of the speakers were more particularly concerned with the problems encountered by research, educational and advisory services.

Opening the general subject, Prof. C. A. Mace (Birkbeck College, London) developed the thesis that much of what is called 'resistance to change' is, in fact, failure in the process of communication. The sources of failure are not entirely at the receiving end; some are in the process of transmission. Quoting Prof. Georges Friedmann's observation that "there has been no technological revolution in most 
of the professions", Prof. Mace went on to explore the prospects of such a revolution in the educational and advisory services. This revolution is coming, he said, through the use, not of precision machines, but of precision techniques. He cited the B.B.C. "Audience Research", a recent report on "Foremanship Training" by A. J. Flook, and a study of "Human Relations Training" by P. Castle, of the National Institute of Industrial Psychology. The essential features of these new techniques of 'precision education' are threefold : the communication, instead of being diffused, is directed to a selected target audience ; it is adapted in content and form to actual needs empirically ascertained; and by suitable 'feedback' devices the impact of the communication is accurately assessed. As the word 'broadcasting' has come to be almost a synonym for 'mass communication', broadcasting the thing is "becoming a technique for focusing a beam of specific intelligence upon a particular public with particular ends in view". The importance of these developments lies in the generality of the principles involved. These principles apply to every form of communication from the poster as simple as "Mind how you go" to the whole curriculum of studies for a B.Sc. degree. They apply to every form of advisory service. Advisory services are essentially concerned with combating resistance to change; but sometimes they themselves are resistant to suggestions for change in the methods they employ. They themselves need to be serviced by advisory research in their problems of communication.

Passing reference was made in the opening paper to certain critical phases in the life of an individual at which variations occur in his "coefficient of resistance to change", and one of these phases was the subject of the second paper, in which Miss M. Woodward (Bedford College, London) reported evidence of "changes in social participation following the birth of a child". In the respects considered, this is a more important event than that of marriage. A survey was made of the membership of societies, the informal relations with friends and working associates, and the leisure pursuits and the interests of 186 women attending a clinic in a dormitory area of London. Impressive facts were adduced regarding the general decrease in a mother's social activity outside the immediate family circle after childbirth. The consequent sense of isolation and increased dependence on the husband for the satisfaction of social needs may, it was suggested, place a serious strain upon marital relations. The findings in this survey acquired additional significance in the context of the symposium. Later speakers were to stress the importance for the diffusion of change of social participation in the life of a group larger than the immediate family circle, and Miss Woodward's observations may contribute to the explanation of the characteristically conservative influence of family life as such.

In the second half of the morning's session, $\mathrm{Mr}$. J. M. Mogey (director of the Oxford Pilot Social Survey) introduced the discussion of resistance to change in agriculture by a historical and anthropological analysis of factors affecting rate of change in the agriculture of Northern Ireland. Owing to physical and historical conditions, Northern Ireland is a country of small-scale farming, and one in which the basic social unit is the farming family. These units have in part been informally organized in clusters of from ten to twelve farms co-operating on the basis of ties of kinship and proximity. New ideas and techniques filtered through to the ordinary farmer only in so far as they fell within the economic potential of the single small farm. In the face of resistance arising from a tradition of informal co-operation, government action in wage control and the promotion of marketing schemes has had only a limited effect. The resistance to official action has been greatest in respect of agricultural education. There has been a failure to work through the informal groups of the countryside. The conclusion was drawn that in a community of small owner-occupiers improvements in farm techniques must be demonstrated by equals. A raising of the level of skill can be expected only through local experiments on the basis of a complete farm. A few successful farms assisted by an advisory service scattered over the countryside and open to visits from neighbours, with the farmer himself explaining the methods employed, would arouse interest and create a desire for more instruction.

Prof. R. Rae (director of the National Agricultural Advisory Services) followed with a discussion of the farmer's attitude to technical advances. He placed high among the factors that influence the farmer's attitude the prospect of reasonable profit from the business of farming. The success of an advisory service depends on the general standard of education of the farmers, and on the introduction of agricultural science to young men in the formative period of their lives. He, too, stressed the importance of demonstrating new methods on farms open to visits from neighbours. He thought that there is no section of the community more receptive to new ideas than the top-grade farmer. In the lowest grade little can be done. In this group there are too many who suffer from the combination of two disabilitiesold age and lack of experience. It is the middle group, the majority, that offers the greatest promise to the advisory services. Farming is essentially a complicated business, and the farmer must be a business man able to organize labour, and so something of a psychologist. In addition, he must be something of an engineer and an economist and must also be a craftsman; and it is an advantage for him to have some understanding of agricultural science. It is this complexity of. requirements which constitutes the reason for the existence of advisory services.

The session concluded with a paper by Dr. Roland Harper (University of Leeds) on psychological aspects of the application of new knowledge and techniques in agriculture. Dr. Harper was concerned with the problems arising in passing scientific knowledge "down the line" from the research laboratory to the farm. The expression brought out the close analogy between the problems of an advisory service and those of the management consultant in promoting communication from higher management to the worker at the bench. It is mainly the psychological factors, Dr. Harper suggested, which prevent the established results of agricultural research from being applied with expedition. He proceeded to review some of the more relevant psychological studies-Lewin's investigation of factors influencing food habits, Ryan and Gross's study of the diffusion of seed corn in Iowa, and Wilkening's "socio-psychological approach to the study of the acceptance of innovations in farming". Expanding the survey, Dr. Harper elucidated some of the general psychological concepts relevant to the problem-motivation and attitudes, social participation and the cognitive aspects of communication. $\mathrm{He}$ concluded with some practical suggestions. His 
analysis reinforced the arguments of previous speakers for operating through informal groups. Much more, he thought, could be done through the guided discussion group. Special emphasis should be placed on means for assessing the success or failure of the methods used by advisory services. $\mathrm{He}$ advocated co-operative research in Great Britain similar to that which he had cited from the United States. He suggested that greater attention should be paid to the attitudes of farmers towards new procedures, and very special attention given to their "uninhibited reactions to our present advisory services".

Contributions to the discussion from the floor were, very appropriately, in the form of such uninhibited reactions of the practical farmers themselves. They reinforced what Dr. Harper and others had said regarding the importance of understanding the needs of those for whom advisory services are provided. It seemed clearly to emerge that scientific advice administered neat is apt to be ineffective. The scientific advisory officer needs to be not only a man of science but also something of a management consultant, competent to advise the farmer in costing the procedures suggested, and able to assist him in adapting general principles to the special circumstances and the particular economy of his farm. This conclusion was in close accordance with an opinion expressed in a conference on farm management organized by the British Institute of Management earlier in the year. A combined scientific and management advisory service is what is most needed. Such a service is of especial importance for the small farmers who comprise the vast majority of those for whom these services are provided.

There would appear, too, to be a substantial body of opinion which favours more detailed and intensive advisory services to a smaller number of farms in preference to a wider service spread more thinly. If it is indeed true that farmers learn more readily from practical demonstrations of successful farming than from the spoken or written word, a well-distributed selection of farms serviced in detail might be more effective than more diffused methods. It is agreed, however, that, whether focused or diffused, advice must be followed up by inquiries whether the advice has been acted on: If not, why not; and if so, with what effect? Follow-up provides the 'knowledge of results', the 'feed back', upon which success depends ; and to make this a routine procedure may be more useful and less expensive than the organization of special attitude and opinion surveys of consumers needs and reactions.

It is of interest to note that, although the symposium was especially concerned with advisory services to the farmer, the policies and principles discussed were of universal application. Regulations continue to multiply, but in all modern civilized societies there is a greater proportionate increase in the use of methods based on advice and persuasion. Advisory services are developing for agriculture, for building and most of the manufacturing industries, and the ordinary citizen has an immense variety of advisory services concerned with his health, his education, his vocational needs, his civil rights and responsibilities. In all these advisory services there is a need for better understanding of the sources of friction and resistance in the channels of communication from the laboratory or the field station to those who have to turn the results of scientific research to practical account.
This was the first joint meeting of the Agriculture and Psychology Sections in the history of the British Association; but with the continued expansion of research and advisory services, it may well be the precursor of many symposia on the psychological aspects of the technique of applying the methods and results of science to human affairs.

\section{BIOLOGICALLY SIGNIFICANT MACROMOLECULES}

A MEETING of Section B (Chemistry) of the British Association took place in Belfast on September 9 before a packed audience under the chairmanship of Prof. M. Stacey (professor of organic and biological chemistry in the University of Birmingham), the subject being "Biologically Significant Macromolecules".

Prof. Stacey spoke on "Polysaccharides of Medical Importance". In the normal functioning of the animal body the synthesis of macromolecules and their subsequent breakdown is of obvious importance. Continuous biological polymerization and depolymerization are essential in growth processes and provide a fascinating study especially in the polysaccharide field. It is perhaps not surprising that the medical applications of complex carbohydrates are becoming of increasing importance.

A good deal is now known regarding the so-called immunologically specific bacterial polysaccharides, especially in the Salmonella and Pneumococcus groups. In the pneumococcus the polysaccharides occur mainly on the surface of the bacterial cell as a capsule from which they may pass into solution in the growth medium of the organism. When they penetrate into the animal body, they stimulate the production of immune proteins, and in vitro in very high dilution they give rise to a specific precipitate on reaction with homologous immune serum. There are more than fifty of these specific polysaccharides, each possessing a different chemical structure, though their physical properties may be similar. A special characteristic is that many of them possess hexosamines and hexuronic acids, in addition to hexoses, as constituent building-units. During recent years, Prof. M. Heidelberger and his colleagues in the United States have shown that the pneumococcus polysaccharides free from protein will immunize human beings against infection, and a mixture of polysaccharides may be used as a prophylactic vaccine against pneumonia. The protection will last up to twelve months, and in large communities the incidence of many types of pneumonia can be lessened.

Vaccines against typhoid, dysentery and cholera, etc., mainly owe their immunizing properties to the presence of a complex carbohydrate residue which contains glucosamine and galactose and which is conjugated to phospholipids and amino-acids.

Seven distinct polysaccharides have been obtained from the mycobacterium which causes tuberculosis in humans, and their specific serological reactions are being studied. When freed from protein, they do not appear to give rise to any immunity. When polysaccharides having molecular weights of the order of a million are degraded by acid or by enzymes, they can often be injected into animals without setting up any immunity in the host. They may, 